\title{
A latent class analysis of adolescents' technology and interactive social media use: Associations with academics and substance use
}

\author{
Sandra Tang ${ }^{1}$ () | Megan E. Patrick ${ }^{2,3}$ (
}

${ }^{1}$ Institute for Social Research, University of Michigan, Ann Arbor, Michigan

${ }^{2}$ Institute for Translational Research in Children's Mental Health, University of Minnesota, Minneapolis, Minnesota

${ }^{3}$ Institute of Child Development, University of Minnesota, Minneapolis, Minnesota

\section{Correspondence}

Sandra Tang, Survey Research Center Population, Neurodevelopment and Genetics Program, Institute for Social Research, University of Michigan, 426 Thompson Street, Ann Arbor, MI 48104-2321.

Email: sandtang@umich.edu

\section{Funding information}

National Institute on Alcohol Abuse and Alcoholism, Grant/Award Number: R01AA023504; National Institute on Drug Abuse, Grant/Award Numbers: R01DA001411, R01DA037902

\begin{abstract}
Latent class analysis was used to identify patterns of technology and social media use among adolescents in a national study $(n=26,348)$. Multinomial logistic regression was used to examine associations between latent classes and academics and substance use. Results demonstrated four classes: Infrequent Users (55\%), Interactive Users (21\%), Television Watchers (14\%), and Constant Users (10\%). Compared to Infrequent Users, Interactive, and Constant Users had lower grades and higher alcohol and marijuana use. Television Watchers had lower grades and participated in fewer extracurricular activities compared to Infrequent Users, but there were no differences on substance use. Results show that adolescents with the most media-intensive profiles were also at greater risk for poor academic outcomes and substance use.
\end{abstract}

\section{KEYWORDS}

academic grades, alcohol, extracurricular activities, marijuana, social media, technology

\section{1 | INTRODUCTION}

The pervasiveness of technology and interactive social media in the lives of adolescents today has led to a growing body of research examining the effects of use on adolescent outcomes. To date, research findings on how technology use is associated with adolescent wellbeing are inconsistent and vary depending on the specific technology or interactive media type examined (for a review, see Tang \& Patrick, 2018). In addition, the majority of research in this area has taken a variable-centered approach, which examines the separate association of each technology and media type on adolescents' outcomes (for an exception, see llakkuvan, Johnson, Villanti, Douglas Evans, \& Turner, 2019). Although a variable-centered approach can provide valuable information, it does not capture the fact that adolescents use a variety of technologies and media and the possibility that the combination rather than any single type is a more meaningful indicator of adolescents' developmental wellbeing. Thus, it is important to use a person-centered approach to understand how adolescents patterns of technology and interactive media use are associated with developmentally important factors.

Two particularly salient and important developmental factors in adolescence are academics and substance use. However, relatively little research has examined how these indicators of wellbeing are associated with use of technology and interactive social media. Academic factors during adolescence, such as school grades and extracurricular activities, are key indicators of adolescent wellbeing and have implications for educational success in college and occupational success in young adulthood (Eccles, Barber, Stone, \& Hunt, 2003; Gardner, Roth, \& Brooks-Gunn, 2008; Geiser \& Santelices, 2007). Similarly, individuals begin to experiment and use substances like alcohol and marijuana during adolescence, and substance use in adolescence is linked to greater odds of substance use later in adulthood (Grant et al., 2006; Kandel, Davies, Karus, \& Yamaguchi, 1986; Schulenberg et al., 2016). Based on unstructured socialization theory (Osgood, Wilson, O'Malley, Bachman, \& Johnston, 1996), which states that unstructured leisure time with peers is associated with more deviant behaviors, greater social media use may be related to poor 
developmental outcomes such as low grades and substance use. The current study will test evidence of this theory and examine how patterns of technology use are associated with academic and substance use outcomes in a national study of youth.

\section{1 | Technology use and academic outcomes}

The associations between use of older, more traditional types of media (e.g., watching television, playing video games) and schoolrelated outcomes are generally consistent across studies. Frequent television watching is associated with less time spent on school work and lower academic grades (Anderson, Huston, Schmitt, Linebarger, \& Wright, 2001; Hancox, Milne, \& Poulton, 2004; Sharif \& Sargent, 2006; Wiecha, Sobol, \& Peterson, 2001). Similarly, studies based on national samples have found that frequent video game playing is associated with lower school grades and test scores (Gentile, 2009; Tang \& Patrick, 2018). Of note, though, is an emerging body of work that emphasizes the cognitive benefits of playing video games (for a review, see Granic, Lobel, \& Engles, 2013).

In contrast to the number of studies examining the association between academic outcomes and traditional types of media, fewer studies have investigated the association between interactive social media use and academic outcomes (Best, Manktelow, \& Taylor, 2014), and most of this work focuses on college students rather than younger adolescents. Existing studies indicate that college students' frequent texting, talking on the phone, and social media use are associated with less homework completion, less studying, and lower grade point average (GPAs) (Jacobsen \& Forste, 2011; Kirschner \& Karpinski, 2010). Similarly, a recent meta-analysis found that frequent online social networking was associated with lower grades (Marker, Gnambs, \& Appel, 2017). Despite research indicating a negative association between social media use and academic outcomes, however, there is some evidence suggesting that college students who used interactive social media, such as Twitter, exhibited higher academic engagement and higher GPAs (Junco, Heibergert, \& Loken, 2010). Few studies, however, have investigated the link between academic engagement measured by participation in extracurricular activities and technology and social media use among adolescents. This is an omission in the literature worth investigating given research findings suggesting that technology and social media use can displace time spent doing more productive activities (Anderson et al., 2001; Sharif \& Sargent, 2006) and contrasting findings suggesting that social media can help facilitate more interaction between individuals and increase participation in extracurricular activities and better educational outcomes (Eccles et al., 2003; Junco, 2012). Together, these studies indicate that the direction of association between academic outcomes and frequent interactive social media use is unclear, especially for younger adolescents, who are typically underrepresented in this area of research. Furthermore, it is unclear how the combination of different types of social media use may be associated with academic outcomes for adolescents.

\section{2 | Technology and substance use}

Similarly, there is limited research on the associations between adolescents' media use and substance use, and the findings from the body of work on this age group vary. One longitudinal study of 9th graders in California found that more frequent television watching, and subsequently greater exposure to alcohol advertisements, predicted onset of drinking in the following year after controlling for demographics and other media use (Robinson, Chen, \& Killen, 1998). A more recent longitudinal study of 7 th graders in North Dakota, however, found that exposure to alcohol advertisements on television did not predict onset of drinking, but exposure to alcohol advertisements in magazines did (Ellickson, Collins, Hambarsoomians, \& McCaffrey, 2005), which highlights that different types of media can have differential effects on adolescents. Less research has examined the association between playing video games and drinking, but a study on Norwegian adolescents found no significant associations between heavy video game playing and drinking (Brunborg, Mentzoni, \& Frøyland, 2014).

Interactive social media has provided another platform for drug-related content to reach adolescents. Content analysis studies of adolescents' social networking websites found frequent references to alcohol use (Egan \& Moreno, 2011; Moreno et al., 2010) and mentions of drug use (Moreno, Parks, \& Richardson, 2007; Moreno, Parks, Zimmerman, Brito, \& Christakis, 2009). Research findings from a national study indicate that adolescents who spend more time on social networking sites are more likely to use alcohol and marijuana in comparison to adolescents who spent no time on social networking sites (CASAColumbia, 2011). Moreover, other studies indicate that the more exposure to alcohol content in mass media, the more positive adolescents' attitudes towards drinking and the more likely they were to drink (Austin \& Knaus, 2000; Fleming, Thorson, \& Atkin, 2004).

Limited studies have investigated the links between use of marijuana and use of technology and interactive social media. Similar to alcohol, a review of the literature suggests that the more marijuana content adolescents see in mass media, the more likely they are to use marijuana (Nunez-Smith et al., 2010). For example, one national study found that adolescents who watched R-rated movies had an increased risk of smoking marijuana (CASAColumbia, 2011). On the other hand, there is evidence that media has positive associations with adolescents' drug use. For example, one study found that television campaigns to reduce marijuana use reversed upward trends in marijuana use for high sensation seekers (Palmgreen, Donohew, Lorch, Hoyle, \& Stephenson, 2001). In alignment with this work, a national study found that adolescents rely on social networking sites to access information on sensitive health topics such as drug use (Lenhart, Purcell, Smith, \& Zickuhr, 2010). Given the limited work in this area, it is unclear whether particular patterns of technology and interactive social media use are associated with adolescent substance use. 


\section{3 | Current study}

The inconsistencies in associations are due, in part, to studies that examine different study populations (e.g., different ages), use convenience sampling or small samples (e.g., college students, nonrepresentative samples), and focus on only one or two types of technology or interactive social media, which may not be representative of how adolescents actually use media overall. In other words, there may be heterogeneity in the combinations of ways in which adolescents use these technologies which in turn may have implications for their academic outcomes and substance use. In addition, the majority of prior research on technology and interactive social media use has employed a variable-centered approach whereby researchers examine how an individual's use of one type of technology and interactive social media (independent of all other types) is associated with a certain outcome. In reality, adolescents rarely use technology and interactive social media singularly and often use them in combination (Carrier, Cheever, Rosen, Benitez, \& Chang, 2009). Although use of one type of technology may not be associated with risky outcomes, it may be the case that certain combinations of technology and interactive social media use indicate risk for adolescents.

Thus, to garner a better understanding of how technology and interactive social media relates to adolescent outcomes, we build upon prior variable-centered work and take a person-centered approach to explore whether distinct and meaningful user profiles can be identified, and to examine whether these combinations of media use behaviors are associated with risky outcomes in adolescence (i.e., poor academic outcomes and substance use). Furthermore, we use national data to examine how technology and interactive social media use cluster together during adolescence, a developmental period when technology and social media use increases dramatically (Rideout, Foehr, \& Roberts, 2010), when academic grades and extracurricular activities become more variable and more powerful predictors of later achievement and career success (Gardner et al., 2008; Geiser \& Santelices, 2007), and when substance use in adolescence is linked to long-term problems in adulthood (Grant et al., 2006; Guo, Hawkins, Hill, \& Abbott, 2001; Schulenberg et al., 2016). Finally, latent class analysis (LCA) is helpful for identifying subgroups that may be at particularly high risk and in need of intervention support focused on technology and social media use, academic support, and/or substance use prevention. In other words, based on reviews of the social media and health promotion literature, interventions are most effective at targeting an audience and enacting change when they take into consideration the demographic profiles of users and their preferred technologies (Korda \& Itani, 2011; Shaw, Mitchell, Welch, \& Williamson, 2015).

Thus, the current study sets out to answer the following questions: (a) are there distinct subgroups of adolescents that engage in particular patterns of technology and interactive social media use, and (b) what are the associations between these subgroups and adolescents' demographic characteristics, and academic (i.e., grades, extracurricular activities) and substance use (i.e., alcohol, marijuana) behaviors?

\section{2 | METHOD}

\section{1 | Sample}

The data for this study are from Monitoring the Future (MTF), an ongoing study that has been administering national cross-sectional surveys of 8th and 10th graders since 1991, with the purpose of investigating trends in risky behaviors such as drinking and drug use, values, and attitudes (Miech et al., 2018). The present study is based on adolescents in Grades 8 and 10 who answered questions related to their technology and interactive social media use during the years 2013-2016. Survey response rates for 8th and 10th graders during these years ranged from 89 to $90 \%$ (Miech et al., 2018). Only adolescents with complete data on the variables of interest were included in this study ( $n=26,348)$. The analytic sample was $48 \%$ male; racial/ethnic breakdown was $58 \%$ White, $15 \%$ Hispanic, $12 \%$ other race/ethnicity, $10 \%$ Black, and $5 \%$ Asian. About half of the sample (47\%) was in 8th grade, and over half of the sample (63\%) had at least one parent with a college degree or higher. Specifically, $6 \%$ of parents had less than a high school degree, $16 \%$ had a high school degree, $15 \%$ had some college, $36 \%$ had a college degree, and $27 \%$ had more than a college degree.

\section{2 | Measures}

Seven technology and interactive social media use measures were used as latent class indicators. All of these measures were dichotomized where 0 = below the sample mean (i.e., low use) and $1=$ above the sample mean (i.e., high use)

\subsubsection{Watch television on a weekday}

Adolescents were asked: "How much TV do you estimate you watch on an average weekday?" Students reported on weekday television using the following options: 1 = "none," 2 = "half hr or less," 3 = "about $1 \mathrm{hr}$," 4 = "about $2 \mathrm{hr}$, " 5 = "about $3 \mathrm{hr}$," 6 = "about $4 \mathrm{hr}, " 7$ = " $5 \mathrm{hr}$ or more." Responses were dichotomized at the mean so that $0=0-2 \mathrm{hr}$ and $1=3+$ hr on an average weekday spent watching television.

\subsubsection{Watch television on a weekend}

Similarly, adolescents were asked: "How much TV do you estimate you watch on an average weekend (both Saturday and Sunday combined)?" Students reported on weekend television using the following options: 1 = "none," $2=$ "half $\mathrm{hr}$ or less," $3=$ "1-2 hr," 4 = "3-4 hr," 5 = "5-6 hr," 6 = "7-8 hr," 7 = "9+ hr." Responses were dichotomized at the mean so that $0=0-6 \mathrm{hr}$ and $1=7+\mathrm{hr}$ on an average weekend spent watching television.

\subsection{3 | Play video games}

Adolescents were asked: "About how many hr a week do you spend playing electronic games on a computer, TV, phone, or other device?" 
Students reported on playing video games using the following options: 1 = "none," 2 = "less than 1 hr," 3 = "1-2 hr," 4 = "3-5 hr," 5 = "6-9 hr," 6 = "10-19 hr," 7 = "20-29 hr," 8 = "30-39 hr," 9 = "40 or more hr." Responses were dichotomized at the mean so that $0=0-9 \mathrm{hr}$ and $1=10+\mathrm{hr}$ per week spent playing video games .

\subsection{4 | Text}

Adolescents were asked: "About how many hr a week do you spend texting on a cell phone?" Students reported on texting using the following options: 1 = "none," 2 = "less than $1 \mathrm{hr}$," $3=$ "1-2 hr," 4 = "3-5 hr," 5 = "6-9 hr," 6 = "10-19 hr," 7 = "20-29 hr," $8=$ "30-39 hr," $9=$ "40 or more." Responses were dichotomized at the mean so that $0=0-9 \mathrm{hr}$ and $1=10+\mathrm{hr}$ per week spent texting.

\subsection{5 | Talk on phone}

Adolescents were asked: "About how many hr a week do you spend talking on a cell phone?" Students reported on talking on the phone using the following options: $1=$ "none," 2 = "less than $1 \mathrm{hr}$," $3=$ "1-2 hr," 4 = "3-5 hr," $5=$ = 6-9 hr," 6 = "10-19 hr," 7 = "20-29 hr," 8 = "30-39 hr," 9 = "40 or more." Responses were dichotomized at the mean so that $0=0-2 \mathrm{hr}$ and $1=3+\mathrm{hr}$ per week spent talking on the phone.

\subsection{6 | Video chat}

Adolescents were asked: "About how many hr a week do you spend video chatting (Skype, etc.)?" Students reported on video chatting using the following options: 1 = "none," 2 = "less than $1 \mathrm{hr}$," 3 = "1-2 hr," 4 = "3-5 hr," 5 = "6-9 hr," 6 = "10-19hr," 7 = "20-29 hr," 8 = "30-39 hr," $9=$ "40 or more." Responses were dichotomized at the mean so that $0=0-2 \mathrm{hr}$ and $1=3+\mathrm{hr}$ per week spent video chatting.

\subsection{7 | Visit social networking websites}

Adolescents were asked: "About how many hr a week do you spend visiting social networking websites like Facebook, Twitter, Instagram, etc.?" Students reported on visiting social networking websites using the following options: 1 = "none," 2 = "less than $1 \mathrm{hr}$, " 3 = "1-2 hr," 4 = "3-5 hr," 5 = "6-9 hr," 6 = "10-19 hr," 7 = "20-29 hr," $8=$ "30-39 hr," $9=$ "40 or more." Responses were dichotomized at the mean so that $0=0-9 \mathrm{hr}$ and $1=10+\mathrm{hr}$ per week visiting social networking websites.

Academic-related and substance use covariates and demographic factors were used to examine associations with the latent classes.

\subsection{8 | High grades}

Adolescents were asked: "Which of the following best describes your average grade in this school year: 9 = "A (93-100)," 8 = "A- (90-92)," $7=$ "B+ (97-89)," 6 = "B (83-86)," 5 = "B- (80-82)," 4 = "C+ (77-79),"
$3=$ "C(73-76)," 2 = "C $-(70-72), " 1=$ "D (69 or below)." For conceptual clarity, responses were recoded into a dichotomous variable to indicate high ( 1 = average of A's and B's) versus low ( $0=$ average of C's and D's) grades. The majority of the sample (83\%) reported having high grades.

\subsection{9 | Homework hours}

Adolescents were asked: "About how many hr do you spend in an average week on all of your homework including both in school and out of school?" Reponses were on a 7-point scale: $1=$ "0 hr," 2 = "1-4 hr," 3 = "5-9 hr," 4 = "10-14 hr," 5 = "15-19 hr," $6=$ "20-24 hr," 7 = "25 or more hr." Responses were dichotomized at the mean where $0=$ spent less than $5 \mathrm{hr}$ and $1=$ spent 5 or more hr per week on homework. About half of the sample (44\%) reported spending 5 or more hr per week (i.e., at least $1 \mathrm{hr}$ per weekday) on homework.

\subsubsection{0 | Participation in extracurricular activities}

Adolescents were asked: "To what extent have you participated in the following school activities [school newspaper or yearbook; music or other performing arts; athletic teams; other school clubs or activities] during this school year?" Responses were on a 5-point scale: 1 = "not at all," 2 = "slight," 3 = "moderate," 4 = "considerable," 5 = "great." A variable representing their level of participation in extracurricular activities was created by averaging all four extracurricular activities and dichotomizing at the mean so that $0=$ no to slight participation (i.e., below the mean) and $1=$ moderate to great participation (i.e., above the mean) in extracurricular activities. About a third of the sample (29\%) reported participating in extracurricular activities a moderate to great extent.

\subsubsection{1 | Substance use}

Two common substances, alcohol and marijuana, used by adolescents were included in this study. Adolescents were asked: "On how many occasions have you had alcoholic beverages to drink-more than just a few sips-during the last 12 months", and "On how many occasions (if any) have you used marijuana (weed, pot) or hashish (hash, hash oil) during the last 12 months?" Two dichotomous variables were created indicating whether the adolescent used alcohol in the last 12 months ( $0=$ no, $1=$ yes $)$ and used marijuana in the last 12 months ( $0=$ no, 1 = yes). About a third of the sample (33\%) reported using alcohol in the last year. A smaller proportion of the sample (19\%) reported having used marijuana in the last year.

\subsubsection{2 | Demographics}

Dichotomous indicators for adolescent gender ( $0=$ female, $1=$ male), grade in school $(0=$ Grade $10,1=$ Grade 8$)$, highest parent educational attainment $(0=$ less than college degree, 1 = college degree or 
higher), and race/ethnicity categories (Black, White [reference], Asian, Hispanic, and Other) were also included.

\section{3 | Analysis}

In the present study, we used LCA, a person-centered approach, to explore the different patterns of technology and interactive social media use among adolescents in the U.S. LCA is used to classify a population into mutually exclusive and exhaustive subgroups based on their patterns across behaviors. In the first step, we selected the number of latent classes based on model fit statistics and interpretability (Collins \& Lanza, 2010). We used the Akaike information criterion (AIC; Akaike, 1974), Bayesian information criterion (BIC; Schwartz, 1978), the sample-sized adjusted Bayesian information criterion (ABIC; Sclove, 1987), and the Vuong-Lo-Mendell-Rubin (VLMR) likelihood ratio test to assess model fit. Lower values for the AIC, BIC, and ABIC indicated more optimal models. Significant $p$-values for the VLMR likelihood ratio test indicated better model fit compared to models with 1 fewer classes.

In the second step, we described the classes of technology and interactive social media use by examining the prevalence of the classes in the population (class membership probability) and the probability of providing particular responses to each item for each class (item-response probability).

In the final step, we used covariates to examine correlations with class membership in a multinomial logistic regression. Specifically, we examined the associations between class membership, demographic characteristics, and academics and substance use using the recommended R3STEP command in Mplus 7.4 (Muthén \& Muthén, 1998), which does not allow covariates to affect latent class formation (Asparouhov \& Muthén, 2015). All analyses accounted for the complex multistage sample design and were weighted to adjust for differential selection probabilities.

\section{3 | RESULTS}

Table 1 presents the descriptive statistics for high frequency of use of all the technology and social media indicator variables (i.e., coded as 1). About a third of the adolescents reported watching television on the weekday, playing electronic video games, and texting at high frequencies. A slightly smaller proportion of adolescents reported frequently visiting social networking sites (27\%) and talking on the phone (25\%). The smallest proportion of adolescents reported video chatting (20\%) and watching television on the weekend (18\%) at high frequencies.

\section{1 | Latent classes of technology and interactive social media use}

Using these seven indicator variables, we estimated and compared latent class models with 2-7 classes using a variety of model selection
TABLE 1 Descriptive statistics of technology and interactive social media use indicators $(n=26,348)$

\begin{tabular}{|c|c|c|}
\hline & Frequency & $\%$ \\
\hline \multicolumn{3}{|l|}{$\begin{array}{l}\text { High frequency of technology and } \\
\text { interactive social media use }\end{array}$} \\
\hline $\begin{array}{l}\text { Watch television for } 3+\text { hr on an } \\
\text { average weekday }\end{array}$ & 7,848 & 30 \\
\hline $\begin{array}{l}\text { Watch television for } 7+\mathrm{hr} \text { in an } \\
\text { average weekend }\end{array}$ & 4,723 & 18 \\
\hline Play video games for $10+\mathrm{hr}$ per week & 7,669 & 30 \\
\hline Text for $10+$ hr per week & 8,019 & 31 \\
\hline Talk on phone for $3+\mathrm{hr}$ per week & 6,467 & 25 \\
\hline Video chat for $3+$ hr per week & 5,037 & 20 \\
\hline $\begin{array}{l}\text { Visit social networking sites for } 10+\mathrm{hr} \\
\text { per week }\end{array}$ & 7,017 & 27 \\
\hline
\end{tabular}

Note: Descriptives reflect when variables are coded 1 (high frequency of use).

criteria to identify the best fitting model. Table 2 displays a range of model fit indices used to compare the 2-7 class models.

As evident from the fit statistics, the AIC, BIC, and ABIC continue to decrease as the number of classes increase, but the decrement in value is relatively small after four classes. Given our large sample size, we were able to conduct a thorough validation of our model selection. We randomly divided our sample into 10 subsets and with each subset, we compared models with 2-7 classes based on a variety of model fit indices (AIC, BIC, ABIC, VLMR). In eight of the subsamples, the fit criteria suggested that the optimal model was the 4-class model (e.g., VLMR $p \leq .01$ ). In two of the subsamples, the fit criteria suggested that the optimal model was the 5-class model. When we compared the interpretability of the classes between the 4- and 5-class models, we found that one of the classes (Infrequent Users) split into two classes, but the difference between the two classes was not substantive. Thus, we chose the more parsimonious model, the 4-class model, as our final model. The final parameter estimates are based on the full sample.

Table 3 presents the prevalence and item-response probabilities for the 4-class model of frequent technology and interactive social media use. The first class labeled Constant Users (about 10\% of the total sample) consisted of adolescents who had high probabilities of being frequent users of all technology and interactive social media. For example, adolescents in this class had a 0.82 probability of watching television $3+\mathrm{hr}$ on an average weekday. Although the probability of video chatting for $3+$ hr per week $(0.48)$ was below 0.50 , the probability was more than twice the sample proportion $(0.20)$, and adolescents in this class had a higher probability of being a frequent video chatter in comparison to all other classes. The second class labeled Interactive Users had the second largest prevalence in the sample with $21 \%$ of the sample classified in this group. Adolescents in the Interactive Users group had a high probability of texting $10+\mathrm{hr}$ per week (0.80), talking on the phone for $3+\mathrm{hr}$ per week (0.56), and visiting social networking sites for $10+\mathrm{hr}$ per week (0.69). Their 
TAB LE 2 Model fit information for latent class analyses $(n=26,348)$

\begin{tabular}{|lllllll}
\hline Number of classes & Log-likelihood & AIC & BIC & ABIC & Entropy & VLMR $p$-value \\
\hline 2 & $-91,632.52$ & $183,295.05$ & $183,417.73$ & $183,370.06$ & 0.78 & \\
\hline 3 & $-89,834.45$ & $179,714.90$ & $179,903.02$ & $179,829.93$ & 0.84 & .00 \\
\hline $4^{\mathrm{a}}$ & $-89,020.22$ & $178,102.44$ & $178,356.00$ & $178,257.48$ & 0.75 & .00 \\
\hline 5 & $-88,683.02$ & $177,444.04$ & $177,763.03$ & $177,639.09$ & 0.69 & .00 \\
\hline 6 & $-88,390.56$ & $176,875.11$ & $177,259.53$ & $177,110.17$ & 0.78 & .00 \\
\hline 7 & $-88,245.03$ & $176,600.07$ & $177,049.92$ & $176,875.13$ & 0.68 & .00 \\
\hline
\end{tabular}

Abbreviations: ABIC, sample-size-adjusted BIC; AIC, Akaike information criterion; BIC, Bayesian information criterion; VLMR, Vuong-Lo-Mendell-Rubin. aselected as final model.

TAB LE 3 Prevalence and item-response probabilities for 4-class model of frequent technology and interactive social media use $(n=26,348)$

\begin{tabular}{|c|c|c|c|c|c|}
\hline \multirow{2}{*}{ Latent class prevalences } & & \multicolumn{4}{|c|}{ Latent classes } \\
\hline & \multicolumn{2}{|l|}{$\begin{array}{l}\text { Sample } \\
\text { proportion }\end{array}$} & \multicolumn{2}{|c|}{ Item-response probabilities } & \\
\hline Play video games for $10+$ hr per week & 0.30 & 0.69 & 0.49 & 0.32 & 0.15 \\
\hline Text for $10+$ hr per week & 0.31 & 0.95 & 0.80 & 0.13 & 0.06 \\
\hline Talk on phone for $3+\mathrm{hr}$ per week & 0.25 & 0.72 & 0.56 & 0.14 & 0.08 \\
\hline Video chat for $3+$ hr per week & 0.20 & 0.48 & 0.38 & 0.11 & 0.08 \\
\hline
\end{tabular}

probabilities of playing video games for $10+\mathrm{hr}$ per week (0.49) and video chatting for $3+\mathrm{hr}$ per week (0.38) were higher than the sample proportion as well. Adolescents in this group also had low probabilities of watching television $3+\mathrm{hr}$ of television on an average weekday (0.14) and watching 7+ hr of television in an average weekend (0.02). In contrast, the third class labeled Television Watchers (14\% of the sample) consisted of adolescents who only had high probabilities of watching $3+\mathrm{hr}$ on an average weekday (0.78) and $7+\mathrm{hr}$ in an average weekend (0.76). For adolescents in this group, the probability of playing video games for $10+\mathrm{hr}$ per week was at the sample proportion. The fourth class labeled Infrequent Users had the largest prevalence in the sample with over half (55\%) of the total sample. Adolescents in this class had low probabilities of high-frequency use of all types of technology and interactive social media.

Finally, given that the analytic sample consisted of adolescents in two grades and the possibility that the latent classes could differ by grade, we also estimated latent classes separately for 8th and 10th graders as a sensitivity test. The best fitting model had the same number of classes with similar substantive interpretations and item-response probabilities as the model that included both grades. Thus, we present the model with the two grades combined for parsimony.

\subsection{Associations between latent class membership and demographic, academic, and substance use variables}

In the last step, we included demographic, academic, and substance use factors in a multinomial logistic regression model to investigate their associations with adolescents' technology and interactive social media use class membership (see Table 4). The largest class, Infrequent Users, was designated as the reference class. In addition, due to the large sample in the present study, a more conservative threshold for significance $(p<.01)$ was used in an effort to reduce potential Type II errors.

Compared to the Infrequent Users class, males had lower odds of being in the Constant Users (odds ratio $[\mathrm{OR}]=0.44, p<.01$ ) or Interactive Users (OR $=0.47, p<.01)$ classes than females. Adolescents who were Black and in the Other race/ethnicity group had higher odds than White adolescents of being in all classes than the Infrequent Users class. In contrast, Asian adolescents were less likely than their White counterparts to be in the Constant Users (OR $=0.47, p<.01)$ and Television Watchers $(\mathrm{OR}=0.59, p<.01)$ classes than Infrequent Users class. Adolescents in Grade 8 had lower odds than those in Grade 10 of being in the Interactive Users than Infrequent Users class (OR $=0.73$, $p<.01$ ). Adolescents with parents with a college degree were less 
TAB LE 4 Latent class multinomial logistic regression: predictors of latent class membership $(n=26,348)$

\begin{tabular}{|c|c|c|c|c|c|c|c|c|c|c|c|c|c|}
\hline & \multicolumn{13}{|c|}{ Latent class } \\
\hline & $b$ & SE & OR & $p$ & $b$ & SE & OR & $p$ & $b$ & SE & OR & $p$ & Infrequent users \\
\hline Intercepts & -1.43 & 0.13 & 0.24 & .00 & -.56 & 0.09 & 0.57 & .00 & -1.02 & 0.10 & 0.36 & .00 & Ref \\
\hline \multicolumn{14}{|l|}{ Demographics } \\
\hline Male (vs. female) & -.83 & 0.07 & 0.44 & .00 & -.76 & 0.05 & 0.47 & .00 & -.04 & 0.06 & 0.96 & .48 & Ref \\
\hline Black & 1.72 & 0.10 & 5.58 & .00 & .27 & 0.10 & 1.30 & .01 & .99 & 0.11 & 2.69 & .00 & Ref \\
\hline Asian & -.76 & 0.28 & 0.47 & .01 & -.36 & 0.17 & 0.70 & .03 & -.53 & 0.17 & 0.59 & .00 & Ref \\
\hline Hispanic & .39 & 0.12 & 1.48 & .00 & -.07 & 0.08 & 0.93 & .39 & .19 & 0.08 & 1.21 & .02 & Ref \\
\hline Other & .77 & 0.10 & 2.17 & .00 & .27 & 0.09 & 1.30 & .00 & .37 & 0.10 & 1.44 & .00 & Ref \\
\hline High grades & -.60 & 0.08 & 0.55 & .00 & -.22 & 0.07 & 0.80 & .00 & -.23 & 0.08 & 0.79 & .00 & Ref \\
\hline $5+$ homework hr & -.03 & 0.08 & 0.97 & .72 & .06 & 0.05 & 1.06 & .27 & .02 & 0.06 & 1.02 & .80 & Ref \\
\hline $\begin{array}{l}\text { Participate in extracurricular } \\
\text { activities }\end{array}$ & .11 & 0.08 & 1.11 & .18 & .12 & 0.06 & 1.13 & .04 & -.20 & 0.07 & 0.82 & .00 & Ref \\
\hline \multicolumn{14}{|l|}{ Substance use } \\
\hline Alcohol use past 12 months & .82 & 0.08 & 2.28 & .00 & .63 & 0.06 & 1.88 & .00 & -.08 & 0.08 & 0.93 & .33 & Ref \\
\hline Marijuana use past 12 months & .39 & 0.09 & 1.47 & .00 & .57 & 0.07 & 1.76 & .00 & -.17 & 0.10 & 0.84 & .10 & Ref \\
\hline
\end{tabular}

Note: Significance at $p<.01$.

Abbreviation: OR, odds ratio.

likely than those with parents with less than a college degree to be in the all other classes, compared to the Infrequent Users class.

For academic-related factors, adolescents with higher grades were more likely to be in the Infrequent Users class compared to all other classes. The number of hr spent on homework was not associated with class membership, but adolescents who participated in extracurricular activities had lower odds of being in the Television Watchers class than the Infrequent Users class (OR $=0.82, p<.01)$.

Finally, adolescents' substance use had similar associations with their technology and interactive social media classification, with Infrequent Users at lowest risk. Adolescents who used alcohol or marijuana in the past year had higher odds of being in the Constant Users $\left(\mathrm{OR}_{\mathrm{alc}}=2.28, p<.01 ; \mathrm{OR}_{\mathrm{mj}}=1.47, p<.01\right)$ or Interactive Users $\left(\mathrm{OR}_{\mathrm{alc}}=1.88, p<.01 ; \mathrm{OR}_{\mathrm{mj}}=1.76, p<.01\right)$ classes than the Infrequent Users class.

\section{4 | DISCUSSION}

Using national data, the present study used a person-centered approach in an attempt to clarify the associations between adolescents' frequent use of technology and interactive social media and school-based outcomes and substance use. The results indicated heterogeneity in how adolescents use technology and interactive social media, and demonstrated that there were four distinct patterns of use among adolescents in the United States. Study results also provided some evidence to support the unstructured socializing theory; results demonstrated that membership in most classes were associated with risky developmental factors such as lower academic grades and higher odds of substance use in comparison to adolescents who used technology and interactive social media infrequently.

Interestingly, the majority of middle and high school-aged adolescents (55\%) did not use technology and interactive social media at high frequencies. One fifth of young adolescents were Interactive Users who did not watch a lot of television, but were frequent users of all other types of technology and interactive social media (i.e., texting $10+\mathrm{hr}$ per week, talking on the phone for $3+\mathrm{hr}$ per week, visiting social networking sites for $10+\mathrm{hr}$ per week). This user group was more likely to have low grades and to have used alcohol and marijuana in the past year. Contrary to prior research with college students (e.g., Junco, 2012), younger adolescent Interactive Users did not participate in more extracurricular activities in comparison to Infrequent Users. It may be the case that extracurricular activities in college are facilitated through social media whereas social media is not as integral a tool for participating in extracurricular activities for younger adolescents. 
The second most common subgroup among adolescents was Television Watchers, who primarily watched television (i.e., watch $3+\mathrm{hr}$ on an average weekday, $7+\mathrm{hr}$ in an average weekend) and used all other types of technology and interactive social media at lower frequencies. Adolescents in this group were more likely to have low grades and less likely to participate in extracurricular activities. This finding is in alignment with research demonstrating that adolescents who watched a lot of television were less engaged in school, led more sedentary lives, and were at higher risk of developing health problems later in life (Hancox et al., 2004; Motl, McAuley, Birnbaum, \& Lytle, 2006; Pagani, Fitzpatrick, \& Barnett, 2010). Thus, these findings highlight that adolescents who frequently watch television are at risk for poor academic outcomes. Additional research focused on this subgroup is needed to identify the types of interventions that can help increase participation in extracurricular activities and engagement in school.

Only a small proportion of young adolescents were so-called Constant Users, who reported frequently using all technology and interactive social media. This group was more likely to have low grades and to have engaged in substance use, especially alcohol, two risky behaviors found to be correlated among adolescents (Bachman et al., 2008). These correlates suggest that adolescents in this subgroup may be particularly prone to seeking out stimulation and thus, frequent users of all types of technology and social media may be one way of identifying young adolescents who may benefit from some intervention in supporting their academic outcomes and curbing their substance use. Given their frequent use of technology and social media, using these modes of prevention delivery may be particularly influential for this high-risk group of adolescents.

\section{1 | Strengths and limitations}

This study had several strengths. One, analyses were based on nationally representative data on 8th and 10th graders in the United States. Two, a variety of technologies and interactive social media types were examined in this study along with important covariates, which allowed us to isolate the association between technology and social media use and adolescents' academic grades, participation in extracurricular activities, and substance use, and control for potentially confounding factors. Three, this study built upon prior variable-centered work and employed a person-centered approach to provide a better understanding of the profiles of different types of high-frequency technology and interactive social media use.

However, this study also had some limitations. One, all analyses are based on cross-sectional data, so the direction of associations cannot be examined. Future research is needed to examine the extent to which these cross-sectional associations are replicated longitudinally, including whether media use affects later behavior and/or whether media use, poor academic outcomes, and substance use are all symptoms of other underlying issues (e.g., internalizing problems). Two, all measures are based on adolescents' self-report in response to survey questions, which are subject to bias because adolescents may not be aware of the amount of time they spend on media and/or because of social desirability. There is evidence to suggest that when adolescents report their media use via surveys, they tend to report higher estimates of use in comparison to what they report via time diaries, though these estimates are correlated (Greenberg et al., 2007). In general, inaccurate estimates of media use may attenuate correlations. The findings from the present study, however, are unlikely to have been affected greatly by this because all measures of media use are based on one form of self-report (surveys) and overestimates of media use are likely to be similar across media forms (Jordan, Trentacoste, Henderson, Manganello, \& Fishbein, 2007). Indeed, self-report via surveys is one of the most commonly used methods of collecting information on adolescents' media use (Jordan et al., 2007). Due to the relatively low cost and low burden on the respondent in comparison to other assessment methods, several other national studies also have relied on self-report via surveys for measuring adolescents' technology and social media use (Lenhart, 2015; Rideout et al., 2010). Yet, there is some concern that surveys may not be the most psychometrically robust method of assessing media use (Vandewater \& Lee, 2009). Future studies may want to examine whether these latent classes are replicated with media use data collected through alternative (and multiple) methods such as, daily diaries, experience sampling methods, and direct observations captured through passive sensors. Lastly, this study did not examine the content of the interactive media used by adolescents because this information was not collected by MTF. It may be the case that the media content may be driving the association with poor developmental outcomes rather than the time spent using media. Future research should use other data to examine this further.

Despite these limitations, the findings from this study provide a unique understanding of how younger adolescents are using technology and social media, and indicate that adolescents who use multiple types of technology and interactive social media at high frequencies also tend to have low grades and engage in substance use. Prevention strategies that address these overlapping risk factors is needed. As other researchers have highlighted (e.g., Korda \& Itani, 2011; Shaw et al., 2015; Wong, Merchant, \& Moreno, 2014), finding ways to leverage high-frequency technology and media use among high risk groups in order to expose them to tailored intervention messaging is one area for additional research.

\section{ACKNOWLEDGMENTS}

The authors would like to thank the Dynamic Links lab for their feedback on the analyses, and a special thanks to Deborah Kloska for her help with data management. In addition, we would like to express our gratitude to the MTF participants for participating in the study. Development of this manuscript was supported by research grants R01DA037902 from the National Institute on Drug Abuse and R01AA023504 from the National Institute on Alcohol Abuse and Alcoholism (both to the second author). Data collection and manuscript preparation were also supported by research grant R01DA001411 from the National Institute on Drug Abuse. The study sponsors had no role in the study design, collection, analysis or interpretation of the data, writing of the manuscript, or the decision to 
submit the paper for publication. The content is solely the responsibility of the authors and does not necessarily represent the official views of the study sponsors.

\section{CONFLICT OF INTEREST}

The authors declare that they have no conflict of interest.

\section{ETHICS STATEMENT}

All procedures performed in studies involving human participants were in accordance with the ethical standards of the institutiona and/or national research committee and with the 1964 Helsinki declaration and its later amendments or comparable ethical standards. Informed consent was obtained from all individual participants included in the study.

\section{ORCID}

Sandra Tang (i) https://orcid.org/0000-0001-8508-6605

Megan E. Patrick (D) https://orcid.org/0000-0003-3594-4944

\section{REFERENCES}

Akaike, H. (1974). A new look at the statistical model identification. IEEE Transactions on Automatic Control, 19, 716-723. https://doi.org/10. 1109/TAC.1974.1100705

Anderson, D. R., Huston, A. C., Schmitt, K. L., Linebarger, D. L., \& Wright, J. C. (2001). Early childhood television viewing and adolescent behavior: The Recontact study. Monographs of the Society for Research in Child Development, 66(1), 1-154.

Asparouhov, T., \& Muthén, B. O. (2015, 14 May). Auxiliary variables in mixture modeling: Using the $\mathrm{BCH}$ method in Mplus to estimate a distal outcome model and an arbitrary secondary model. Mplus Web Notes \#21, version 2. Retrieved from http://www.statmodel.com/examples/ webnotes/webnote21.pdf

Austin, E. W., \& Knaus, C. (2000). Predicting the potential for risky behavior among those 'too young' to drink as the result of appealing advertising. Journal of Health Communication, 5, 13-27. https://doi.org/10. 1080/108107300126722

Bachman, J. G., O'Malley, P. M., Schulenberg, J. E., Johnston, L. D., Freedman-Doan, P., \& Messersmith, E. E. (2008). The education-drug use connection: How successes and failures in school relate to adolescent smoking, drinking, drug use, and delinquency. New York, NY: Taylor \& Francis Group.

Best, P., Manktelow, R., \& Taylor, B. (2014). Online communication, social media and adolescent wellbeing: A systematic narrative review. Children and Youth Services Review, 41, 27-36. https://doi.org/10.1016/j. childyouth.2014.03.001

Brunborg, G. S., Mentzoni, R. A., \& Frøyland, L. R. (2014). Is video gaming, or video game addiction, associated with depression, academic achievement, heavy episodic drinking, or conduct problems? Journal of Behavioral Addictions, 3(1), 27-32. https://doi.org/10.1556/JBA.3. 2014.002

Carrier, L. M., Cheever, N. A., Rosen, L. D., Benitez, S., \& Chang, J. (2009). Multitasking across generations: Multitasking choices and difficulty ratings in three generations of Americans. Computers in Human Behavior, 25, 483-489. https://doi.org/10.1016/j.chb.2008.10.012
CASAColumbia. (2011, June). Adolescent substance use: America's \#1 public health problem. New York, NY: The National Center on Addiction and Substance Abuse at Columbia University.

Collins, L. M., \& Lanza, S. T. (2010). Latent class and latent transition analysis: With applications in the social, behavioral, and health sciences. Hoboken, NJ: John Wiley \& Sons.

Eccles, J. S., Barber, B. L., Stone, M., \& Hunt, J. (2003). Extracurricular activities and adolescent development. Journal of Social Issues, 59(4), 865-889. https://doi.org/10.1046/j.0022e-4537.2003.00095.x

Egan, K. G., \& Moreno, M. A. (2011). Alcohol references on undergraduate males' Facebook profiles. American Journal of Men's Health, 5(5), 413-420. https://doi.org/10.1177/1557988310394341

Ellickson, P. L., Collins, R. L., Hambarsoomians, K., \& McCaffrey, D. F. (2005). Does alcohol advertising promote adolescent drinking? Results from a longitudinal assessment. Addiction, 100(2), 235-246. https:// doi.org/10.1111/j.1360-0443.2005.00974.x

Fleming, K., Thorson, E., \& Atkin, C. K. (2004). Alcohol advertising exposure and perceptions: Links with alcohol expectancies and intentions to drink or drinking in underaged youth and young adults. Journal of Health Communication, 9(1), 3-29. https://doi.org/10.1080/ 10810730490271665

Gardner, M., Roth, J., \& Brooks-Gunn, J. (2008). Adolescents' participation in organized activities and developmental success 2 and 8 years after high school: Do sponsorship, duration, and intensity matter? Developmental Psychology, 44(3), 814-830. https://doi.org/10.1037/00121649.44.3.814

Geiser, S., \& Santelices, M. V. (2007). Validity of high-school grades in predicting student success beyond the freshman year: High-school record vs. standardized tests as indicators of four-year college outcomes. In Research \& occasional paper series: CSHE.6.07. Berkeley, CA: Center for Studies in Higher Education, University of California. Retrieved from https://escholarship.org/uc/item/7306zOzf

Gentile, D. A. (2009). Pathological video-game use among youth ages 8 to 18: A national study. Psychological Science, 20(5), 594-602. https:// doi.org/10.1111/j.14679280.2009.02340.x

Granic, I., Lobel, A., \& Engles, R. C. M. E. (2013). The benefits of playing video games. American Psychologist, 69(1), 1-13. https://doi.org/10. $1037 / \mathrm{a} 0034857$

Grant, J. D., Scherrer, J. F., Lynskey, M. T., Lyons, M. J., Eisen, S. A., Tsuang, M. T., ... Bucholz, K. K. (2006). Adolescent alcohol use is a risk factor for adult alcohol and drug dependence: Evidence from a twin design. Psychological Medicine, 36(1), 109-118. https://doi.org/10. 1017/S0033291705006045

Greenberg, B. S., Eastin, M. S., Skalski, P., Cooper, L., Levy, M., \& Lachlan, K. (2007). Comparing survey and diary measures of internet and traditional media use. Communication Reports, 18(1-2), 1-8. https://doi.org/10.1080/08934210500084164

Guo, J., Hawkins, J. D., Hill, K. G., \& Abbott, R. D. (2001). Childhood and adolescent predictors of alcohol abuse and dependence in young adulthood. Journal of Studies on Alcohol, 62(6), 754-762. https://doi. org/10.15288/jsa.2001.62.754

Hancox, R. J., Milne, B. J., \& Poulton, R. (2004). Association between child and adolescent television viewing and adult health: A longitudinal birth cohort study. The Lancet, 364(9430), 17-23. https://doi.org/10.1016/ S0140-6736(04)16675-0

llakkuvan, V., Johnson, A., Villanti, A. C., Douglas Evans, W., \& Turner, M. (2019). Patterns of social media use and their relationship to health risks among young adults. Journal of Adolescent Health, 64, 158-164. https://doi.org/10.1016/j.jadohealth.2018.06.025

Jacobsen, W. C., \& Forste, R. (2011). The wired generation: Academic and social outcomes of electronic media use among university students. Cyberpsychology, Behavior and Social Networking, 14(5), 275-280. https://doi.org/10.1089/cyber.2010.0135

Jordan, A., Trentacoste, N., Henderson, V., Manganello, J., \& Fishbein, M. (2007). Measuring the time teens spend with media: Challenges and 
opportunities. Media Psychology, 9(1), 19-41. https://doi.org/10. 1080/15213260709336801

Junco, R. (2012). The relationship between frequency of Facebook use, participation in Facebook activities, and student engagement. Computers \& Education, 58(1), 162-171. https://doi.org/10.1016/j. compedu.2011.08.004

Junco, R., Heibergert, G., \& Loken, E. (2010). The effect of twitter on college student engagement and grades. Journal of Computer Assisted Learning, 27, 119-132. https://doi.org/10.1111/j.1365-2729.2010. 00387.x

Kandel, D. B., Davies, M., Karus, D., \& Yamaguchi, K. (1986). The consequences in young adulthood of adolescent drug involvement: An overview. Archives of General Psychiatry, 43(8), 746-754. https://doi.org/ 10.1001/archpsyc.1986.01800080032005

Kirschner, P. A., \& Karpinski, A. C. (2010). Facebook ${ }^{\circledR}$ and academic performance. Computers in Human Behavior, 26(6), 1237-1245. https://doi. org/10.1016/j.chb.2010.03.024

Korda, H., \& Itani, Z. (2011). Harnessing social media for health promotion and behavior change. Health Promotion Practice, 14(1), 15-23. https:// doi.org/10.1177/1524839911405850

Lenhart, A. (2015, April). Teen, social media and technology overview 2015. Washington, DC: Pew Research Center.

Lenhart, A., Purcell, K., Smith, A., \& Zickuhr, K. (2010, February). Social media and young adults. Washington, DC: Pew Internet \& American Life Project. Retrieved from http://www.pewinternet.org/Reports/ 2010/Social-Media-and-Young-Adults.aspx

Marker, C., Gnambs, T., \& Appel, M. (2017). Active on Facebook and failing at school? Meta-analytic findings on the relationship between online social networking activities and academic achievement. Educational Psychology Review, 30(3), 651-677. https://doi.org/10.1007/s10648017-9430-6

Miech, R. A., Johnston, L. D., O'Malley, P. M., Bachman, J. G., Schulenberg, J. E., \& Patrick, M. E. (2018). Monitoring the future national survey results on drug use, 1975-2017. In Secondary school students (Vol. I). Ann Arbor, MI: Institute for Social Research, The University of Michigan. Retrieved from http://monitoringthefuture.org/ pubs/monographs/mtf-vol1_2017.pdf

Moreno, M. A., Briner, L. R., Williams, A., Brockman, L., Walker, L., \& Christakis, D. A. (2010). A content analysis of displayed alcohol references on a social networking web site. Journal of Adolescent Health, 47(2), 168-175. https://doi.org/10.1016/j.jadohealth.2010. 01.001

Moreno, M. A., Parks, M. R., \& Richardson, L. P. (2007). What are adolescents showing the world about their health risk behaviors on MySpace? Medscape General Medicine, 9(4), 9.

Moreno, M. A., Parks, M. R., Zimmerman, F. J., Brito, T. E., \& Christakis, D. A. (2009). Display of health risk behaviors on MySpace by adolescents: Prevalence and associations. Archives of Pediatric Adolescent Medicine, 163(1), 27-34. https://doi.org/10.1001/ archpediatrics.2008.528

Motl, R. W., McAuley, E., Birnbaum, A. S., \& Lytle, L. A. (2006). Naturally occurring changes in time spent watching television are inversely related to frequency of physical activity during early adolescence. Journal of Adolescence, 29(1), 19-32. https://doi.org/10.1016/j. adolescence.2005.01.005

Muthén, L. K., \& Muthén, B. O. (1998-2015). Mplus user's guide: Seventh edition. Los Angeles, CA: Muthén \& Muthén.

Nunez-Smith, M., Wolf, E., Huang, H. M., Chen, P. G., Lee, L., Emanuel, E. J., \& Gross, C. P. (2010). Media exposure and tobacco, illicit drugs, and alcohol use among children and adolescents: A systematic review. Substance Abuse, 31(3), 174-192. https://doi.org/10. 1080/08897077.2010.495648

Osgood, D. W., Wilson, J. K., O'Malley, P. M., Bachman, J. G., \& Johnston, L. D. (1996). Routine activities and individual deviant behavior. American Sociological Review, 61(4), 635-655. https://doi.org/10.2307/2096397
Pagani, L. S., Fitzpatrick, C., \& Barnett, T. A. (2010). Prospective associations between early childhood television exposure and academic, psychosocial, and physical well-being by middle childhood. Archives of Pediatrics and Adolescent Medicine, 154(5), 425-431. https://doi.org/ 10.1001/archpediatrics.2010.50

Palmgreen, P., Donohew, L., Lorch, E. P., Hoyle, R. H., \& Stephenson, M. T. (2001). Television campaigns and adolescent marijuana use: Tests of sensation seeking targeting. American Journal of Public Health, 91(2), 292-296. https://doi.org/10.2105/ajph.91.2.292

Rideout, V. J., Foehr, U. G., \& Roberts, D. F. (2010). Generation $M^{2}$ media in the lives of 8-to 18-year-olds. Menlo Park, CA: Henry J. Kaiser Family Foundation.

Robinson, T. N., Chen, H. L., \& Killen, J. D. (1998). Television and music video exposure and risk of adolescent alcohol use. Pediatrics, 102(5), e54. https://doi.org/10.1542/peds.102.5.e54

Schulenberg, J. E., Patrick, M. E., Kloska, D. D., Maslowsky, J., Maggs, J. L., \& O'Malley, P. M. (2016). Substance use disorder in early midlife: A national prospective study on health and well-being correlates and long-term predictors. Substance Abuse: Research and Treatment, 9s1(S1), 9. https://doi.org/10.4137/SART.S31437

Schwartz, G. (1978). Estimating the dimension of a model. Annals of Statistics, 6, 461-464. https://doi.org/10.1214/aos/1176344136

Sclove, S. L. (1987). Application of model-selection criteria to some problems in multivariate analysis. Psychometrika, 52, 333-343. https://doi. org/10.1007/bf02294360

Sharif, I., \& Sargent, J. D. (2006). Association between television, movie, and video game exposure and school performance. Pediatrics, 118(4), e1061-e1070. https://doi.org/10.1542/peds.2005-2854

Shaw, J. M., Mitchell, C. A., Welch, A. J., \& Williamson, M. J. (2015). Social media used as a health intervention in adolescent health: A systematic review of the literature. Digital Health, 1, 1-10. https://doi.org/10. $1177 / 2055207615588395$

Tang, S., \& Patrick, M. E. (2018). Technology and social interactive media use among 8th and 10th graders in the U.S. and associations with homework and school grades. Computers in Human Behavior, 85, 34-44. https://doi.org/10.1016/j.chb.2018.04.025

Vandewater, E. A., \& Lee, S. J. (2009). Measuring children's media use in the digital age: Issues and challenges. American Behavioral Scientist, 52(8), 1152-1176. https://doi.org/10.1177/0002764209331539

Wiecha, J.L., Sobol, A.M., Peterson, K.E., \& Gortmaker, S.L. (2001). Household television access: Associations with screen time, reading, and homework among youth. Ambulatory Pediatrics, 1(5), 244-251. https:// doi.org/10.1367/1539-4409(2001)001<2044:HTAAWS>2.0.CO;2

Wong, C. A., Merchant, R. M., \& Moreno, M. A. (2014). Using social media to engage adolescents and young adults with their health. Healthcare (Amsterdam, Netherlands), 2(4), 220-224. https://doi.org/10.1016/j. hjdsi.2014.10.005

\section{AUTHOR BIOGRAPHIES}

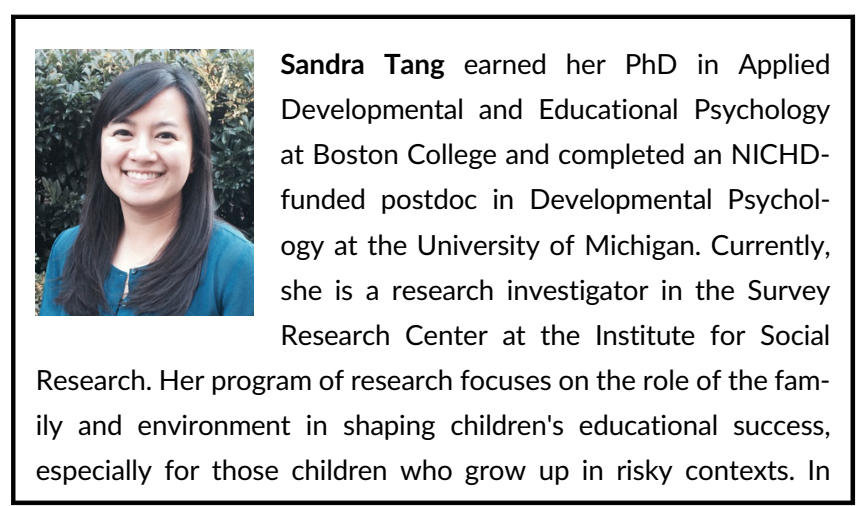


particular, she is interested in using longitudinal data to understand the extent to which cultural, socioeconomic, and environmental factors shape family socialization processes, and in turn, children's educational and developmental outcomes. Ultimately, the goal of her work is to identify potential policy and intervention targets for supporting the positive development of children and youth growing up in disadvantaged environments.

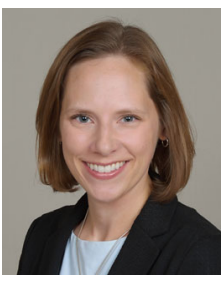

Megan E. Patrick, PhD, is a research professor at the Institute for Translational Research and the Institute of Child Development at the University of Minnesota. Her published research focuses on the development and consequences of adolescent and young adult substance use and other risk behaviors. Her interests include motivation and decision-making, the prevention of health risk behaviors, statistical methods for modeling behavior and behavior change, and mobile and web-based survey methodology. She has had continuous research funding from the National Institutes of Health since 2007. Currently funded projects include a focus on high-intensity drinking among adolescents and young adults, dynamic associations between substance use and consequences across young adulthood, predictors and consequences of simultaneous alcohol and marijuana use, and dynamic interventions for substance use. She is also a co-investigator of the national Monitoring the Future study which provided data for the current analysis.

How to cite this article: Tang S, Patrick ME. A latent class analysis of adolescents' technology and interactive social media use: Associations with academics and substance use. Hum Behav \& Emerg Tech. 2020;2:50-60. https://doi.org/10. 1002/hbe2.154 